\title{
Relationships of Scincid Lizards (Mabuya spp; Reptilia: Scincidae) from the Cape Verde Islands Based on Mitochondrial and Nuclear DNA Sequences
}

\author{
A. Brehm,* J. Jesus,* M. Pinheiro,† and D. J. Harrisł, ${ }^{1}$ \\ *Centro de Ciências Biologicas e Geologicas, University of Madeira, Penteada, 9000 Funchal, Portugal; †Centro de Zoologia, \\ Instituto de Investigacao Cientifica Tropical, M inisterio da Ciência e Tecnologia, Lisbon, Portugal; and ‡Centro de Estudos \\ de Ciência Animal (CECA), ICETA-U.P., Campus Agrario de Vairão, 4485-661 Vila do Conde, Portugal
}

Received October 24, 2000; revised January 25, 2001

Partial DNA sequences from two mitochondrial (mt) and one nuclear gene (cytochrome b, 12S rRNA, and C-mos) were used to estimate the phylogenetic relationships among the six extant species of skinks endemic to the Cape Verde Archipelago. The species form a monophyletic unit, indicating a single colonization of the islands, probably from West Africa. Mabuya vaillanti and $M$. delalandii are sister taxa, as indicated by morphological characters. Mabuya fogoensis and $M$. stangeri are closely related, but the former is probably paraphyletic. Mabuya spinalis and M. salensi s are also probably paraphyletic. Within species, samples from separate islands al ways form monophyletic groups. Some colonization events can be hypothesized, which are in line with the age of the islands. C-mos variation is concordant with the topology derived from mtDNA. ๑ 2001 Academic Press

Key Words: Mabuya; Cape Verde; cytochrome b; 125 rRNA; C-mos phylogeny; colonization.

\section{INTRODUCTION}

Studies of among-island variation have been fundamental in evolutionary theory. Nonvolant tetrapod groups, such as lizards, have become model organisms for the study of colonization and dispersal patterns, especially in the mid-Atlantic islands which have wellknown geological histories (e.g., Thorpe et al., 1994; Brown and Pestano, 1998; Carranza et al., 2000). Initial colonization of these archipelagos has often been followed by invasion of nearby islands and rapid speciation (Carranza et al., 2000). Reconstruction of such events can be assessed with DNA sequence data. Given the limited range of these island endemic species and that island populations have a higher risk of extinction

${ }^{1}$ To whom correspondence should be addressed. Fax: +351 252 661780. E-mail: james@mail.icav.up.pt.
(Frankham, 1997), assessment of variation is also critical for conservation efforts.

The Cape VerdeArchipelago lies $450 \mathrm{~km}$ from the West African Coast and comprises 10 islands and 3 islets of volcanic origin which have never been connected to the mainland (Mitchell-Thomé, 1983). The set configuration is of an arch (Fig. 1), the oldest islands being Maio, Sal, and Boavista and the youngest being Santo Antão and Brava, the tips of the "arch." Because the sea depth between islands varies from a few meters to more than 3 $\mathrm{km}$ it is probable that some of them were linked due to sea level fluctuations during the Pleistocene or even more recently. During these periods some of the northwestern group of islands were most likely linked-São Vicente, Santa Lucia, Branco, and Raso, and possibly also Boavista and Maio from the "central" group of islands. Apart from these cases the water channels are very deep (>1000 m) so it is highly improbable that these islands were ever linked by land connections.

The genus Mabuya comprises species of skinks of moderate to large size, with cylindrical bodies (Hoogmoed, 1974). They have a worldwide distribution in tropical and subtropical areas with approximately 101 described species. In the Cape Verde islands the genus is represented by 6 recognized species, the only diurnal lizards present, all of which are endemic to the archipelago (Table 1). The giant scincid Macroscincus coctei was another endemic species but it is believed to have been extinct from the beginning of the twentieth century (Schleich, 1982). The taxonomic status of some of these 6 species remains controversial especially at the subspecific level (e.g., Mertens, 1955; Schleich, 1987; J oger, 1993). Based on morphological characters, the two sympatric species $M$. delalandii and M. vaillanti are considered to form a closely related group (Greer, 1976; Pinheiro, 1989; J oger, 1993). They possess fused interparietals and parietals (unique in skinks) and retain 26 presacral vertebrae, which is typical in Mabuya (Greer et al., 2000). The remaining species in the Cape Verde islands usually have 27 presacral vertebrae. M. 


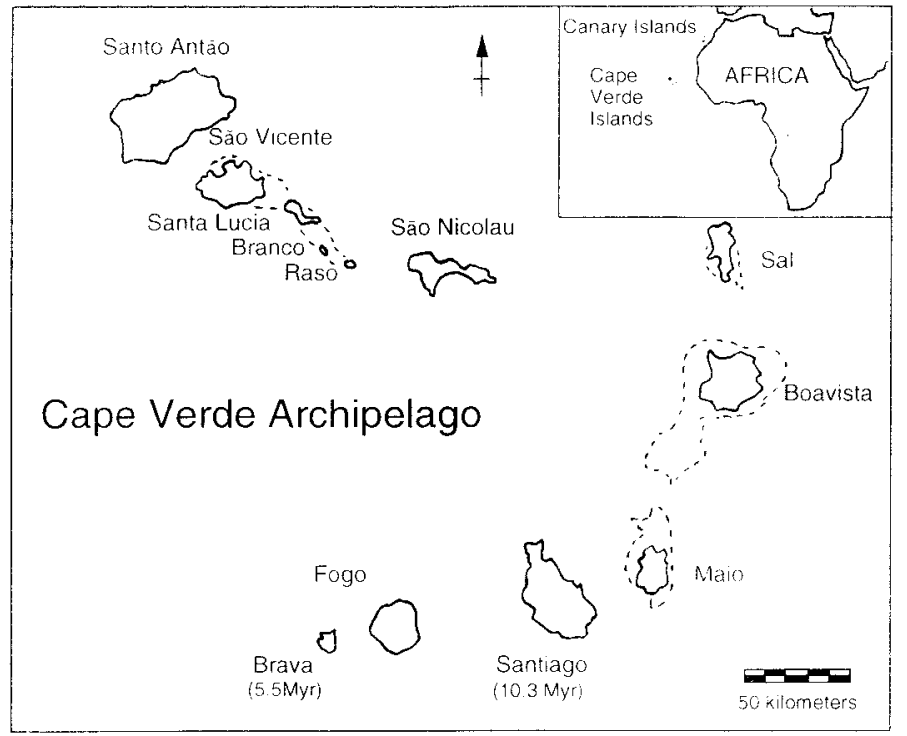

FIG. 1. Map of the Cape Verde islands. Localities of specimens used in this study are given in Table 1 . Shallow water areas, which were probably above sea level in the geologically recent past, are marked with dashed lines.

delalandii and $M$. vaillanti are restricted to the leeward islands of the Archipelago; Brava, Fogo, and Santiago. M. fogoensis is distributed on the windward islands of Santo Antão and São Nicolau and is divided into two endemic subspecies, M. f. antaoensis and M. f. nicol auensis (Schleich, 1987). The remaining 3 species, M. stangeri, M. salensis, and M. spinalis, share several morphological characteristics and have been the center of most of the taxonomic controversy (Angel, 1935; Mertens, 1955; Schleich, 1987; J oger, 1993). Based on morphological characters J oger (1993) proposed that all Scincidae from the Cape Verde islands, including the extinct giant skink $M$. coctei, are a monophyletic group presumably from the nearby West African coast. However, recent molecular analyses of the Cape Verde island geckos Tarentola (Carranza et al., 2000) and Hemidactylus ( esus et al., 2001) infer multiple colonizations in Hemi dactylus and a direct colonization from the more distant Canary I slands in the case of Tarentola. Mitochondrial DNA evidence suggests that Mabuya may have colonized Madagascar more than once (Mausfield et al., 2000). Therefore, the monophyletic status of Mabuya in the islands and its probable origin require further investigation.

Here we examine Mabuya from the Cape Verde Archipelago, covering almost the entire distribution of the extant species. On the basis of mitochondrial and nuclear DNA sequences, we elucidate the phylogenetic relationships among species and address historical dispersal processes that may have shaped their present distribution pattern.

\section{MATERIALS AND METHODS}

The geographic locations of the specimens used in this study, voucher codes, and number of specimens used are given in Table 1. All specimens belong to the collections of the University of Madeira. Total genomic DNA was extracted from small pieces of tail by use of standard methods. Polymerase chain reaction (PCR) primers used in both amplification and sequencing were cytochrome b1 and 2 and 12Sa and 12Sb from Kocher et al. (1989) and G73 and G74 for C-mos from Saint et al. (1998). Amplification conditions were the same as those described by Harris et al. (1998, 1999). Amplified fragments were sequenced from both strands on a 373 Applied Biosystem DNA Sequencing Apparatus. Sequences from the cytochrome $b$ and $12 S$ rRNA bel onging to the same individual were merged in the subsequent analysis. These and the C-mos sequences were aligned with Clustal W (Thompson et al., 1994). Cytochrome b, 12SrRNA, and C-mos sequences were, respectively, 280, 333, and 375 bp long. Three species of Mabuya from the Africa/Madagascar group, $M$. affinis, $M$. elegans, and $M$. quinquetaeniata (Mausfield et al., 2000), and Chal cides ocel latus and C. viridis from the Canary Islands (Brown and Pestano, 1998) were included in the analysis of the mtDNA sequences. The mtDNA sequences were aligned with Clustal W (Thompson et al., 1994). The cytochrome b sequences contained no indels. The data were then imported into PAUP* 4.0b3a (Swofford, 2000) for phylogenetic analysis. When estimating phylogenetic relationships among sequences, one assumes a model of evolution. Determining which model is most appropriate for a given data set is a statistical problem (Goldman, 1993). We used the approach outlined by Huelsenbeck and Crandall (1997) to test 56 alternative models of evolution, employing PAUP* 4.0b3a and Modeltest (Posada and Crandall, 1998). A starting tree was obtained with neighbor-joining. With this tree, likelihood scores were calculated for various models of evolution and then compared statistically with a $\chi^{2}$ test with degrees of freedom equal to the difference in free parameters between the models being tested. The null hypotheses tested in this way included (1) nucleotide frequencies are equal, (2) transition rates are equal to transversion rates, (3) there is only one transition rate, (4) there are only two transversion rates, (5) there is rate homogeneity among sites, and (6) there is no significant proportion of invariable sites. Once a model of evolution was chosen, it was used to estimate a tree with the minimum-evolution (ME) optimality criteria (Rzhetsky and Nei, 1992). Support for nodes was estimated using the bootstrap (Felsenstein, 1985) technique, with 1000 replicates. A maximum-parsimony (MP) analysis was also carried out (100 replicate heuristic search), and support for nodes was estimated with decay analysis (Bremmer, 1988) and bootstrapping with 1000 repli- 
TABLE 1

List of Specimens and Locations Used in This Study

Species (number included for mtDNA)

M. fogoensis (O'Shaughnessy, 1874) $)^{1}(6)$

M. fogoensis (O'Shaughnessy, 1874) ${ }^{1}$ (3)

M. stangeri (Gray, 1845) ${ }^{2}(1)$

M. stangeri (Gray, 1845) $)^{2}(2)$

M. s. maioensis Mertens, $1955^{3}(2)$

M. spinalis Boulenger, $1906^{4}(2)$

M. spinalis Boulenger, $1906^{4}(2)$

M. salensis Angel $1935^{5}$ (1)

M. salensis Angel, $1935^{5}(2)$

M. vaillanti Boulenger, 1887 (2)

M. vaillanti Boulenger, 1887 (2)

M. delalandii (Dumeril \& Bibron, 1839) ${ }^{6}$ (1)

M. delalandii (Dumeril \& Bibron, 1839) ${ }^{6}$ (3)

M. delalandii (Dumeril \& Bibron, 1839) ${ }^{6}$ (3)
Voucher code

Island locality

R34, 35, 36, 80, 100, cv133

Santo Antão

$\mathrm{R} 01,72,93$

R78

$\mathrm{R} 76,86$

R66, 67, 69

$\mathrm{R} 61,62$

R60, cv58

$\mathrm{R} 03$

R79, 82

R92, 94, 96

R98, 00, rvst999

R55

$\mathrm{R} 43,49,51$

R52, 98, 99
São Nicolau

São Vicente

Ilhéu Raso

Maio

Fogo

Santiago

Boavista

Sal

Fogo

Santiago

Brava

F ogo
Santiago

\footnotetext{
${ }^{1}$ Formerly attributed to the genus Euprepes but renamed by Boulenger, 1887 as Mabuya fogoensis; Schleich (1987) created two new subspecies for Santo Antão and São Nicolau, respectively, M. f. antaoensis and M. f. nicolauensis.

${ }^{2}$ Formerly attributed to the genus Euprepes but renamed by Boulenger, 1887 as Mabuya stangeri.

${ }^{3}$ Renamed M. spinalis maioensis by J oger (1993).

${ }^{4}$ Considered a synonym of M. stangeri by Schleich (1987), but J oger (1993) reassigned it as M. spinalis subspecies spinalis.

${ }^{5}$ Initially designated M. salensis by Angel (1935) and then changed to M. stangeri (Dekeyser and Villiers, 1951). Mertens (1955) and Schleich (1982) created a subspecies M. stangeri salensis with the terra typica in the island of Sal. J oger (1993) refers M. spinalis salensis Angel, 1935 to the specimens from Boavista and Sal islands and M. spinalis maioensis Mertens, 1955 to the specimens from Maio island.

${ }^{6}$ First attributed to the genus Euprepes but renamed by Boulenger, 1887.
}

cates. Assessment of saturation in the third positions of the cytochrome $b$ by the plotting of numbers of transitions and transversions against uncorrected distances indicated that these position were not saturated (not shown). Therefore, all positions were included in the analysis.

\section{RESULTS}

We obtained $613 \mathrm{bp}$ of aligned sequences from the combined 12S rRNA and cytochrome $b$ genes for 32 taxa. GenBank Accession Nos. are AF335016AF 335088. With the included published data this gave 35 representatives of Mabuya and 2 Chalcides, which were designated outgroups. Using Modeltest (Posada and Crandall, 1998) under the Akaike information criteria, we concluded that the GTR model (Rodríguez et al., 1990), with a gamma-distributed rate heterogeneity model (four rate categories, $G=0.85$; Yang, 1994) and an estimated proportion of invariant sites (0.56) was the most appropriate model of evolution for this data. A 10-replicate heuristic search with this model produced a single tree with a minimum-evolution score of 1.4 (Fig. 2). Maximum-parsimony analysis found two trees of 515 steps which were similar to the ME tree (Fig. 2); 158 characters were parsimony informative. For the nuclear gene C-mos, nine sequences of $375 \mathrm{bp}$ were analyzed. Eleven positions were variable, and 6 positions were parsimony informative. There were no insertions or deletions. Since there was no homoplasy in the data set, the sequences were joined in a most parsimonious network. As all the synapomorphies were in agreement with the topology derived from mtDNA data, they were simply mapped onto the ME tree (Fig. 2). Inclusion in the analysis of C-mos sequences (from Saint et al., 1998) of other skinks from the same subfamily Lygosominae (Greer, 1970; Honda et al., 2000) did not alter this topology.

\section{DISCUSSION}

With the available outgroups, the mitochondrial DNA sequences suggest that the Mabuya from the Cape Verde islands are a monophyletic clade. Within the islands, they can be separated into two groups. One is constituted by $M$. vaillanti from Fogo and Santiago and the sympatric $M$. delalandii, which also occurs in the island of Brava. The separation of these species from the others is in accordance with morphological characters. Both of these species are monophyletic, with 99-100\% bootstrap support from the mtDNA analysis and a single synapomorphy in the C-mos sequence data. In M. delalandii low variation was found in individuals from different islands, and no variation was found within islands. In the distance analysis $M$. vaillanti samples are separated according to their island of origin, but with MP the two individuals from Santiago were successive branches to the two from Fogo.

The other main branch comprises all remaining species studied. This branch can also be subdivided into two groups. One contains $M$. fogoensis from Santo 


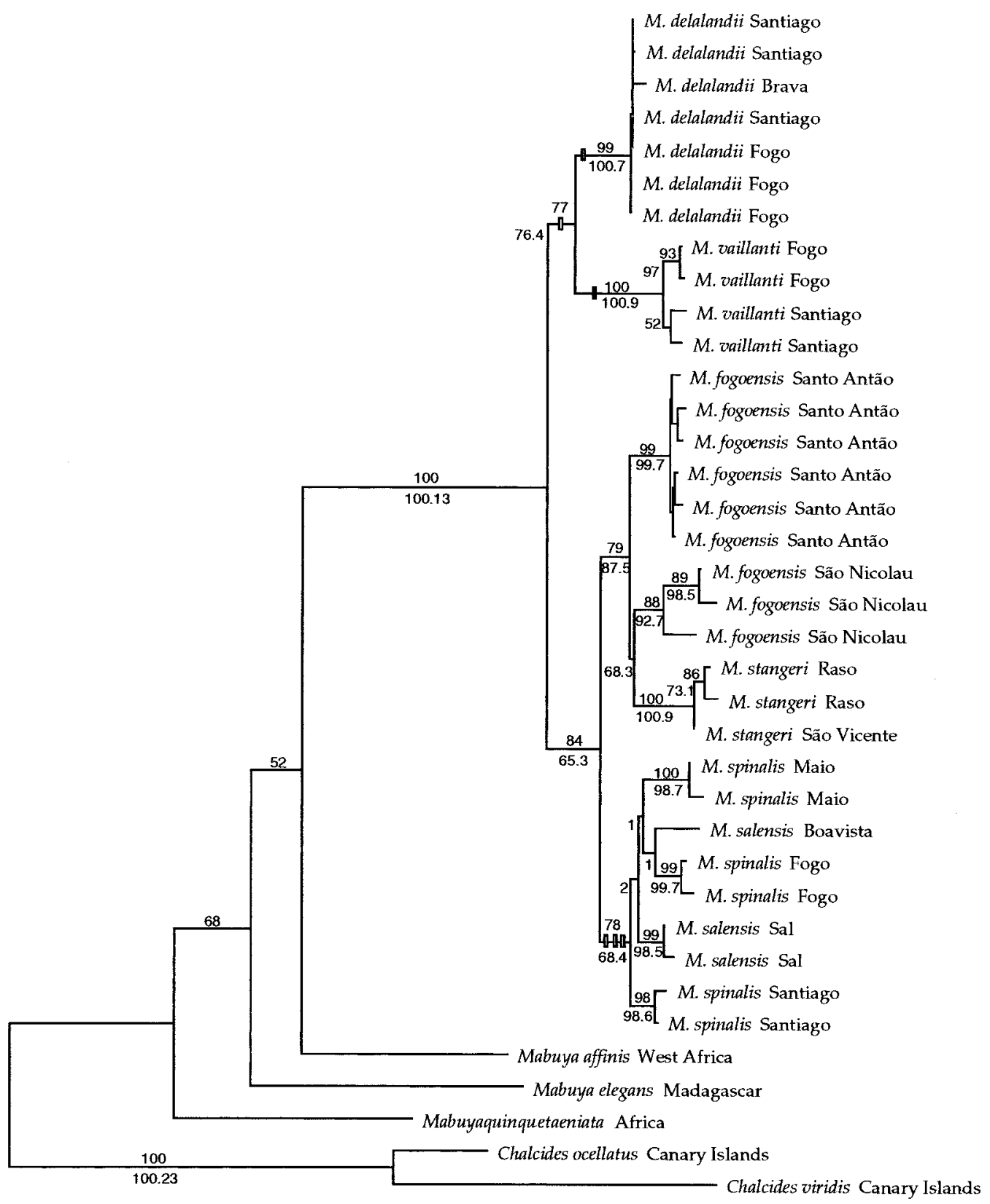

FIG. 2. Tree derived from a minimum-evolution (ME) search using the model described in the text. Maximum-parsimony (MP) trees differed in that M. vaillanti from Santiago was not a monophyletic group and that the three Mabuya outgroup taxa were joined as a clade (61\% bootstrap support). Bootstrap values (>50\%) for ME and MP are given above and below nodes, respectively. Decay indices for the MP analysis are given bel ow the nodes. The tree was rooted with the Chalcides sequences. Six synapomorphies derived from $\mathrm{C}$-mos sequences are mapped onto the tree (open rectangles).

Antão and São Nicolau and M. stangeri from São Vicente and the islet of Raso. The population from São Nicolau has been regarded by some as a separate subspecies from M. fogoensis of Santo Antão with the name M. fogoensis nicolauensis (e.g., Schleich, 1987). In our ME analysis M. fogoensis is paraphyletic, with $M$. stangeri more closely related to $M$. fogoensis from Santo Antão. When we constrained $M$. fogoensis to be monophyletic and compared this against the ME tree with the same model of evolution with the likelihood variance (KH) test of Kishino and Hasegawa (1989), the hypothesis could not be refuted (differences in -In $\mathrm{I}=0.35, \mathrm{P}=0.7$ ). Whereas the use of the $\mathrm{KH}$ test has recently been questioned, in this case, since we reject the null hypothesis with a $\mathrm{P} / 2>0.05$, our results would be the same using the alternative Shimodaira and Hasegawa test (see Goldman et al., 2000). Therefore, we cannot reject the possibility that M. fogoensis 
is monophyletic. However, the samples from the two islands are clearly morphol ogically and genetically distinct. M. stangeri from São Vicente and Raso are closely related (100\% bootstrap support), which is not surprising if one takes into consideration that the islands were probably united during recent glacial periods. This scenario agrees with Greer's (1976) hypothesis of evolution of the extinct giant skink $M$. coctei, which was known from the islands of Raso and Branco and regarded by this author as derived from either $M$. fogoensis or $\mathrm{M}$. stangeri.

The third group of species includes M. salensis (from Sal and Boavista islands), M. spinal is from Santiago and $\mathrm{Fogo}$, and samples from Maio that have been referred to either $M$. stangeri or $M$. spinalis. Both mtDNA (78\% bootstrap) and three synapomorphies from the C-mos sequences support this clade. Within the group all the islands that were sampled form monophyletic units (98-100\% support from mtDNA), but relationships between the islands are very poorly supported. In the ME tree the two species do not form monophyletic units, but this possibility cannot be significantly rejected using the $\mathrm{KH}$ test. Based upon our analysis, the samples from Maio should be considered $M$. spinalis maioensis rather than $M$. stangeri, supporting J oger (1993).

Due to the lack of support for relationships within the M. spinalis/ M. salensis clade, little can be hypothesized about colonization patterns for these species. However, the possible radiation in other species can be predicted. M. delalandii and M. vaillanti may have originated and speciated on Santiago, which is the oldest of the islands on which they are found and the closest to Africa. Separate colonizations of F ogo, and in the case of $M$. delalandii, Brava, would then have occurred. If one assumes a molecular clock of $1.9 \%$ per million years (after Carranza et al., 2000), the two speciated approximately 3 mya, with M. vaillanti colonizing Fogo 1 mya and $M$. delalandii even more re cently. These dates are much more recent than the origin of the islands. In the $M$. fogoensis/ M. stangeri clade, higher genetic variation is found within $M$. $f$. nicolauensis, on the older more eastern island of São Nicolau, and from here the lizards could have successively colonized the newer more western islands of São Vicente and Santo Antão.

\section{CONCLUSIONS}

Analysis of mtDNA sequence variation resolves many of the relationships within Mabuya from the Cape Verde islands, and the limited C-mos variation is in concordance with these. Variation within Mabuya is lower than that found among geckos on the islands (Carranza et al., 2000; J esus et al., 2001), implying a more recent colonization. Intraisland colonization events also appear to be fewer. This is not surprising, as geckos generally are more successful transmarine colonizers, as indicated by their presence on more oceanic islands, than skinks. Further, some geckos may have been moved between islands anthropogenically (J esus et al., 2001).

Mitochondrial DNA still reveals considerable variation between islands, which helps the understanding of the systematics of the group and is essential knowledge for their future conservation. Many taxa have very restricted ranges, and, given that $M$. coctei has probably al ready gone extinct in the last century, more work will be needed to ensure their continuing existence.

\section{ACKNOWLEDGMENTS}

We are grateful to L. Carvalho of the Secretaria Executiva para o Ambiente from the Cape Verde government and ICCTI of Lisbon for assistance in funding surveys in the Cape Verde Islands. Thanks go to three reviewers whose constructive comments improved the manuscript.

\section{REFERENCES}

Angel, F. (1935). Sur la faune herpétologique de l'Archipel du Cap Vert. XII Congr. Int. Zool. IX: 1693-1700.

Bremmer, K. (1988). The limits of amino acid sequence data in angiosperm phylogenetic reconstruction. Evolution 42: 795- 803.

Brown, R. P., and Pestano, J. (1998). Phylogeography of skinks (Chalcides) in the Canary Islands inferred from mitochondrial DNA sequences. Mol. Ecol. 7: 1183-1191.

Carranza, S., Arnold, E. N., Mateo, J . A., and Lopez-J urado, L. F. (2000). Long-distance colonization and radiation in gekkonid lizards, Tarentola (Reptilia: Gekkonidae), revealed by mitochondrial DNA sequences. Proc. R. Soc. Lond. B. 267: 637- 649.

Dekeyser, P. L., and Villiers, A. (1951). Mission J . Cadernat aux Iles du Cap Vert. Bull. Inst. Français d'Afriques Noir 13: 1152-1158.

Felsenstein, J. (1985). Confidence limits on phylogenies: An approach using the bootstrap. Evolution 39: 783-791.

Frankham, R. (1997). Do island populations have less genetic variation than mainland populations? Heredity 78: 311-327.

Goldman, N. (1993). Simple diagnostic statistical tests of models of DNA substitution. J . Mol. Evol. 37: 650-651.

Goldman, N., Anderson, J . P., and Rodrigo, A. G. (2000). Likelihoodbased tests of topologies in phylogenetics. Syst. Biol. 49: 652- 670.

Greer, A. E. (1970). A subfamilial classification of scincid lizards. Bull. Mus. Comp. Zool. 139: 151-183.

Greer, A. (1976). On the evolution of the giant Cape Verde scincid lizard Macroscincus coctei. J . Nat. Hist. 10: 691-712.

Greer, A. E., Arnold, C., and Arnold, E. N. (2000). The systematic significance of the number of presacral vertebrae in the scincid lizard genus Mabuya. Amphibia-Reptilia 21: 121-126.

Harris, D. J ., Arnold, E. N., and Thomas, R. H. (1998). Rapid speciation, morphological evolution and adaptation to extreme environments in Sand Lizards (Meroles) as revealed by mitochondrial gene sequences. Mol. Phylogenet. Evol. 10: 37- 48.

Harris, D. J ., Sinclair, E. A., Mercader, N. L., Marshall, J . C., and Crandall, K. A. (1999). Squamate relationships based on C-mos nuclear sequences. Herpetol. J . 9: 147-151.

Honda, M., Ota, H., Kobayahi, M., Nabhitabhata, J ., Yong, H.-S., and Hikida, T. (2000). Phylogenetic relationships, character evolution, and biogeography of the subfamily Lygosominae (Reptilia: Scinci- 
dae) inferred from mitochondrial DNA sequences. Mol. Phylogenet. Evol. 15: 452- 461.

Hoogmoed, M. S. (1974). Ghanese lizards of the genus Mabuya (Scincidae, Sauria, Reptilia). Zool. Verhand. 138: 3- 61.

Hulsenbeck, J. P., and Crandall, K. A. (1997). Phylogeny estimation and hypothesis testing using maximum likelihood. Annu. Rev. Ecol. Syst. 28: 437-466.

J esus, J., Brehm, A., Pinheiro, M., and Harris, D. J. (2001). Relationships of Hemidactylus (Reptilia: Gekkonidae) from the Cape Verde Islands: What mitochondrial DNA data indicate. J . Herpetol., in press.

J oger, U. (1993). On two collections of reptiles and amphibians from the Cape Verde Islands, with descriptions of three new taxa. Courier Forsch. Inst. Senckenberg 159: 437- 444.

Kishino, H., and Hasegawa, M. (1989). Evaluation of the maximum likelihood estimate of the evolutionary tree topologies from DNA sequence data, and the branching order in Hominoidea. J. Mol. Evol. 29: 170-179.

Kocher, T. D., Thomas, W. K., Meyer, A., Edwards, S. V., Pääbo, S., Villablanca, F. X., and Wilson, A. C. (1989). Dynamics of mitochondrial evolution in animals: Amplification and sequencing with conserved primers. Proc. Natl. Acad. Sci. USA 86: 6196-6200.

Mausfeld, P., Vences, M., Schmitz, A., and Veith, M. (2000). First data on the molecular phylogeography of the scincid lizards of the genus Mabuya. Mol. Phylogenet. Evol. 17: 11-14.

Mertens, R. (1955). Die Eidechsen der Kapverden. Soc. Sci. Feb. Comment. Biol. 15: 1-16.

Mitchell-Thome, R. C. (1983). Radiometric studies in Macronesia. Bol. Mus. Mun. Funchal. 37: 52- 85.

Pinheiro, M. (1989). Mabuya delalandii (Dum. \& Bibr.) e Mabuya vaillanti Blgr. (Sauria, Scincidae) do arquipélago de Cabo Verde. Garcia de Orta Sér. Zool. 13: 49-55.

Posada, D., and Crandall, K. A. (1998). Modeltest: Testing the model of DNA substitution. Bioinformatics 14: 817-818.

Rodríguez, F., Oliver, J . F., Marín, A., and Medina, J . R. (1990). The general stochastic model of nucletide substitutions. J . Theor. Biol. 142, 485-501.

Rzhetsky, A., and Nei, M. (1992). A simple method for estimating minimum evolution trees. Mol. Biol. Evol. 9: 945-967.

Saint, K. M., Austin, C. C., Donnellan, S. C., and Hutchinson, M. N. (1998). C-mos, a nuclear marker useful for squamate phylogenetic analysis. Mol. Phylogenet. Evol. 10: 259-263.

Schleich, V. (1982). Vorläufige Mitteilungen zu Herpetofauna der Kapverden. CFS - Courier 52: 245-248.

Schleich, V. (1987). Herpetofauna Caboverdiana. Spixiana 12: 1-75.

Swofford, D. L. (2000). PAUP*: Phylogenetic Analysis Using Parsimony (and other methods) 4.0.b3a. Sinauer, Sunderland, MA.

Thompson, J . D., Higgins, D. G., and Gibson, T. J . (1994). Clustal W: I mproving the sensitivity of progressive multiple sequence alignment through sequence weighting, position specific gap penalties and weight matrix choice. Nucleic Acid. Res. 22: 4673- 4680.

Thorpe, R. S., McGregor, D. P., Cumming, A. M., and J ordan, W. C. (1994). DNA evolution and colonization sequence of island lizards in relation to geological history: mtDNA RFLP, cytochrome $b$, cytochrome oxidase I, 12S rRNA sequence and nuclear RAPD analysis. Evolution 48: 230-240.

Yang, Z. (1994). Maximum likelihood phylogenetic estimation from DNA sequences with variable rates over sites: Approximate methods. J . Mol. Evol. 39: 306-314. 